\title{
Do Human Papilloma Viruses Play Any Role in Oral Squamous Cell Carcinoma in North Indians?
}

\author{
Vineeta Singh ${ }^{1,3}$, Nuzhat Husain ${ }^{1 *}$, Naseem Akhtar ${ }^{2}$, Vijay Kumar ${ }^{2}$, Shikha \\ Tewari $^{1}$, Sridhar Mishra ${ }^{1}$, Sanjeev Misra ${ }^{2}$, M.Y. Khan ${ }^{3}$
}

\begin{abstract}
Background: Oral squamous cell carcinoma (OSCC) is the most prevalent malignancy among males in India. While tobacco and alcohol are main aetiological factors, human papilloma virus (HPV) presence has surprisingly increased in head and neck Squamous Cell Carcinoma (HNSCC) in the past two decade but its frequency in OSCCS is still uncertain. We aim to explore the frequency of HPV and its major genotypes in North Indian patients and their association with clinicopathological and histopathological features and p16 expression pattern. Materials and Methods: The study group comprised 250 histologically proven cases of OSCC. HPV was detected by real time PCR in tumor biopsy specimens and confirmed by conventional PCR with PGMY09/ PGMY11 primers. Genotyping for high-risk types 16/ 18 was conducted by type specific PCR. p16 expression was assessed by immunohistochemsitry. Results: HPV presence was confirmed in 23/250 (9.2\%) OSCC cases, of which $30.4 \%$ had HPV 16 infection, $17.4 \%$ were positive for HPV 18 and $26.1 \%$ had co-infections. HPV presence was significantly associated with male gender $(\mathrm{p}=0.02)$ and habit of pan masala chewing $(\mathrm{p}=0.01)$. HPV positive cases also had a history of tobacco consumption in $91.3 \%$ cases. p16 over expression was observed in $39.1 \%$ of HPV positive cases but this was not significantly different from negative cases $(p=0.54)$. Conclusions: The frequency of HPV in OSCC is low in North-India and majority of cases are associated with a tobacco habit. It appears that tobacco shows a confounding effect in HPV positive cases and use of p16 protein as a reliable marker to assess the potential etiological role of HPV in OSCC in our population is not suggested.
\end{abstract}

Keywords: Oral squamous cell carcinoma - human papilloma virus - p16 - head \& neck squamous cell carcinoma.

Asian Pac J Cancer Prev, 16 (16), 7077-7084

\section{Introduction}

Oral squamous cell carcinoma (OSCC) is one of the most prevalent malignancy in India with approximately 83,000 new cases and more than 46,000 deaths occur yearly (Bray et al., 2013). It ranks number one in terms of incidence among men and third among women (Byakodi et al., 2012). According to Indian Council of Medical Research there is a sharp increase in the number of oral cancer cases by 2020 is expected.

In India $16 \%$ population smoke tobacco, $20 \%$ chew tobacco/pan masala and $30 \%$ either smoke or chew tobacco (Rani et al., 2003) and these are the well established risk factors for OSCC. The relative risk for OSCC among tobacco and alcohol abusers is 20 times that of non-smokers and non-drinkers (Hashibe et al., 2009).

An increased involvement of human papilloma virus (HPV) in the Head \&Neck Squamous Cell Carcinoma (HNSCC) has been reported in past 10 years (Chaturvedi et al., 2008) but its presence is not as consistent in it as in cervical cancer and therefore its actual prevalence is still vague in HNSCC and need the more solemn attention of researchers in this direction.

HPV is a DNA virus that presents tropism for epithelial cells, causing infection of the skin and mucous membrane. Its presence is more allied to oropharyngeal cancer for instance about $40-80 \%$ of oropharyngeal cancers are caused by HPV in USA, whereas in Europe the proportion varies from around $90 \%$ in Sweden to less than $20 \%$ in communities with the highest rates of tobacco use (Marur et al., 2010).

The etiologic role of HPV in HNSCC sites other than oropharynx is still controversial. In India a wide variation in HPV associated OSCC has been reported, for instance in Western India only 15\% OSCC patients showed association with HPV, $33.6 \%$ cases in Eastern India while its prevalence is surprisingly higher $(70.6$ $\%$ ) in South Indian population (Balaram et al., 1995; D'Costa et al., 1998; Priya et al., 2005; Alok et al., 2006; Chaudhary et al., 2013). These variations might be due

${ }^{1}$ Department of Pathology, Dr. Ram Manohar Lohia Institute of Medical Sciences, ${ }^{2}$ Department of Surgical Oncology, King George's Medical University, ${ }^{3}$ Department of Biotechnology, Babasaheb Bhimrao Ambedkar University, Lucknow, UP, India *For correspondence:drnuzhathusain@hotmail.com 
to sensitivity of the employed technique, the sample size, the state of conservation of the clinical specimens, and epidemiological factors of the studied population.

Apart from having a different epidemiology and aetiology, the HPV-positive HNSCC are different clinicopathologically and showed distinct histopathology. These are usually poorly differentiated, nonkeratinizing and have a basaloid appearance (Gillison et al., 2000). Furthermore, patients with HPV-positive HNSCC in general tend to be younger at time of diagnosis (Smith et al., 2004) and generally have a better survival and favorable prognosis compared to the HPV-negative patients (Hafkamp et al., 2008; Lassen et al., 2009).

HPV positive oral cancer also represents a distinct molecular phenotype with a unique mechanism of tumorigenesis, independent of the mutagenic effect of tobacco and alcohol. A characteristic over expression of p16, tumor suppressor protein, has been observed in HPV positive HNSCC. Two viral onco-proteins E6 and E7 cause inactivation of $\mathrm{p} 53$ and retinoblastoma $(\mathrm{Rb})$ respectively, this event leads further activation of CDKN2A gene and increased expression of $\mathrm{p} 16$ has occurred. Thus, $\mathrm{p} 16$ overexpression is an indicator of an aberrant expression of viral oncogenes and considered as a surrogate biomarker for HPV presence (Klussmann et al., 2009; Ahmed et al., 2012).

Therefore, the present study aims to explore the frequency of HPV association in OSCC, distribution of its major high risk types and correlation with other risk factors in North Indian population.

\section{Materials and Methods}

Study Population: A total of 250 clinically and histologically proven cases of OSCC were included prospectively in the study between Oct 2013 to Jan 2015. Tissue biopsies were collected from department of Surgical Oncology, King George's Medical University (KGMU) Lucknow after obtaining approval from the Institutional Ethics Committee and written informed consent from the patients.

Sample Collection: Tissue biopsies were collected in $10 \%$ buffered formalin at RT for histopathological diagnosis and in $1 \mathrm{X}$ phosphate buffer saline (PBS, pH 7.4) and stored at $-80^{\circ} \mathrm{C}$ for molecular analysis. The demographic and clinical details of the patients were recorded on the standard questionnaire.

DNA Extraction: The DNA from biopsy tissues was isolated by commercially available Genomic DNA Mini kit (Invitrogen, USA) as per manufacturer's instructions. The extracted DNA was eluted in $80 \mu$ of the elution buffer (provided in the kit) and kept at $-80^{\circ} \mathrm{C}$ until further use. All the DNA samples were qualitatively confirmed on $0.8 \%$ agarose gel electrophoresis and the concentration and purity was checked by DS-11 spectrophotometer (Denovix, USA) at 260/280 nm wavelengths.

HPV detection: HPV detection was performed by using the following methodology

Real Time PCR based methodology for HPV detection: Presence of HPV in OSCC samples were detected by Real time PCR (Biorad CFX 96 ${ }^{\mathrm{TM}}$ ) using 13 HIGH RISK HPV REAL TIME PCR KIT (Hybribio Limited, China) as per manufacturer's instructions. Briefly, each PCR reaction contained $17.5 \mu 1$ of PCR master mix, $0.5 \mu 1$ of Taq DNA polymerase and $2 \mu 1$ of DNA. The PCR amplification protocol was as follows- initial denaturation at $95^{\circ} \mathrm{C}$ for $10 \mathrm{~min}$ and 45 cycles of - denaturation for $3 \mathrm{~min}$ at $95^{\circ} \mathrm{C}$, annealing for $60 \mathrm{sec}$ at $60^{\circ} \mathrm{C}$, and extension at $72^{\circ} \mathrm{C}$ for $20 \mathrm{sec}$. The amplification was followed by a $5 \mathrm{sec}$ final extension step at $38^{\circ} \mathrm{C}$. Presence or absence of HPV DNA was confirmed by the $\mathrm{Ct}$ values obtained for the sample.

Conventional PCR based methodology: Further validation of HPV was done using PGMY09/11 primers as reported by P.E.Gravitt et al; 2000, designed to amplify a 450bp HPV L1 gene fragment. This region is used because it is highly conserved between different HPV types but has sufficient variation for the identification of each one. Cervical cancer cases which were confirmed previously for HPV presence were used as positive control. PCR amplification was carried out in a volume of $20 \mu \mathrm{l}$ containing $50 \mathrm{ng} / \mu \mathrm{l}$ of genomic DNA, $4 \mathrm{mM}$ of $\mathrm{MgCl} 2$ (Invitrogen, USA), $200 \mu \mathrm{M}$ of each dNTPs. Concentration of PGMY09/11 primers was reduced from $10 \mathrm{pmol}$ as previously used to $5 \mathrm{pmol}$, also the final concentration of AmpliTaq DNA polymerase (Invitrogen, USA) was reduced from $7.5 \mathrm{U} / \mu 1$ to $5 \mathrm{U} / \mu 1$. Amplification was performed in thermal cycler (S100 ${ }^{\mathrm{TM}}$, Biorad, USA) under the following conditions: initial denaturation at $95^{\circ} \mathrm{C}$ for $9 \mathrm{~min}$, followed by 35 cycles of $-95^{\circ} \mathrm{C}$ for $1 \mathrm{~min}$ (denaturation), primer annealing at $55^{\circ} \mathrm{C}$ for $1 \mathrm{~min}$, extension at $72^{\circ} \mathrm{C}$ for $1 \mathrm{~min}$ and a final extension at $72^{\circ} \mathrm{C}$ for $5 \mathrm{~min}$. Positive and negative controls were run simultaneously.

HPV genotyping: Samples that were positive for HPV presence were proceeded further for high risk HPV 16 \& 18 genotyping. HPV genotyping was done with the previously described type specific primers for HPV 16 and 18 (Sharma et al., 2005). PCR amplification was carried out in a $20 \mu \mathrm{l}$ reaction volume containing $50 \mathrm{ng} / \mu \mathrm{l}$ of genomic DNA, 10pmol each of forward and reverse primer, $2 \mathrm{mM} \mathrm{MgCl} 2$ (Invitrogen, USA), $200 \mu \mathrm{M}$ of each dNTPs, $0.5 \mathrm{U} / \mu 1$ of AmpliTaq DNA polymerase (Invitrogen, USA) along with 10X (NH4)2SO4 buffer (Invitrogen, USA). Amplification was performed in thermal cycler $\left(\mathrm{S} 100^{\mathrm{TM}}\right.$, Biorad, USA) under the following PCR conditions: An initial denaturation at $94^{\circ} \mathrm{C}$ for $10 \mathrm{~min}$, followed by 35 cycles of $94^{\circ} \mathrm{C}$ for $1 \mathrm{~min}$ (cycle denaturation), primer annealing at $52^{\circ} \mathrm{C}$ for $1 \mathrm{~min}$ for HPV $16 \& 62^{\circ} \mathrm{C}$ for $1 \mathrm{~min}$ for HPV 18 , extension at $72^{\circ} \mathrm{C}$ for $1 \mathrm{~min}$ and a final extension of $72^{\circ} \mathrm{C}$ for $5 \mathrm{~min}$. PCR products were confirmed for their respective amplicon size on $2 \%$ agarose gel electrophoresis and visualized by UV-transillumination (Gel Doc XR+, Biorad, USA).

Expression of p16 by Immunohistochemsitry (IHC): Paraffin-embedded tissues were sectioned, $4 \mu \mathrm{m}$, using a microtome (Leica, Germany), and transferred to tissue bond-coated slides (Biocare, USA). After overnight incubation in a $60^{\circ} \mathrm{C}$ dry oven, paraffin-embedded sections were deparaffinized in xylene and rehydrated through graded ethanol series $100 \%, 70 \%$ and $50 \%$. Endogenous peroxidase activity was blocked with $3 \%$ 
hydrogen peroxide in methanol for $30 \mathrm{~min}$. Antigen retrieval was done by placing the slides in Tris-EDTA buffer ( $\mathrm{pH}$ 9.0) in Pascal. These sections after cooling to room temperature (RT) were incubated with p16 primary antibody (Biogenex) at RT for one hour, followed by treatment with polymer based secondary antibody kit with DAB (DAKO, Denmark). Positive reactions were visualized using diaminobenzidine, DAB (1:50). Sections were finally counter-stained with $0.1 \%$ hematoxylin. The positive cells expressing the p16 positivity were assessed for cytoplasmic as well as nuclear staining at higher magnification.A tumor was recorded positive if more than $10 \%$ of tumor cells showed immunoreactivity (Names et al., 2006).

Data analysis: The diagnostic criteria used for the detection of HPV considered only those OSCC cases that were positive by at least two methods described above (Real time PCR, PCR, 16 PCR \& 18 PCR). The real time PCR data was analyzed using Bio-Rad CFX Manager software v3.0. The results are presented in mean \pm SD and percentages. The Chi-square test was used to compare the dichotomous/categorical variables and unpaired t-test was used to compare the continuous variables. The univariate binary logistic regression was carried out to find the strength of associations. The odds ratio with its confidence interval was calculated. The $\mathrm{p}$-value $<0.05$ was considered significant. Kaplan-Meier survival curve was made and survival time was compared by using Log rank test. All the analysis was carried out by using SPSS 16.0 version (Chicago, Inc., USA).

\section{Results}

The study encompasses 250 histologically proven cases of OSCC. Out of these HPV presence was confirmed in $23(9.2 \%)$ cases (Figure 1A\&B) according to diagnostic criteria predefined in data analysis. Table 1 summarizes the clinical, histopathological, demographic and behavioral characteristics of patients in HPV positive and negative cases.

The mean age of HPV positive patients was 47.17 while HPV negative cases had mean age 47.69 , but this difference was statistically insignificant. HPV presence associated significantly with male gender $[\mathrm{p}=0.02 *, \mathrm{OR}$ $(95 \% \mathrm{CI})=0.34(0.13-0.83)]$. Buccal Mucosa was the most frequent site $(52.2 \%)$ in patients. Most of HPV positive cases were well differentiated SCC (60.9\%), eight cases were moderately differentiated or keratinized while only $4.3 \%$ cases showed a basaloid morphology (Figure 2A). HPV positivity did not find to be associated with age, marital status, domicile, sub-site, stage, tumor grade, nodal status and outcome.

In HPV positive cases $91.3 \%$ had taken tobacco in any form while only $8.7 \%$ patients had no history of any risk factor. History of multiple risk factors was present in $13.00 \%$ cases. HPV positivity significantly associated with habit of pan masala chewing $[\mathrm{p}=0.01 *, \mathrm{OR}(95 \% \mathrm{CI})$ $=0.32(0.13-0.79)]$.

HPV subtypes in OSCC: Out of 23 HPV positive cases $30.4 \%$ cases had HPV 16 infection while $17.4 \%$ were positive for HPV 18. Six cases $(26.1 \%)$ co-expressed
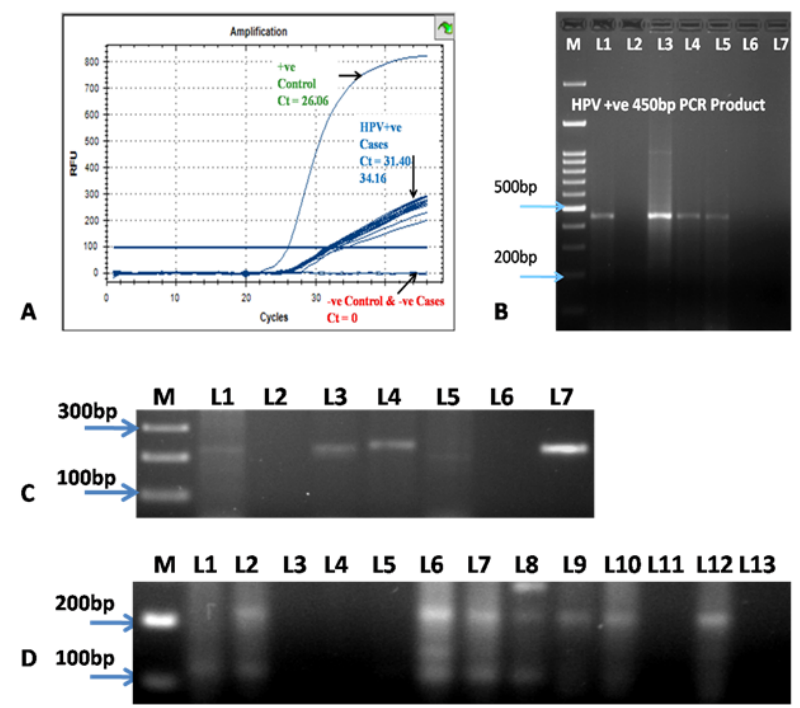

Figure 1. Detection of HPV by real time and conventional PCR. (A) Amplification Plot by Real Time PCR, (B) 2\% Agarose gel with amplified product of HPV (450bp) by PGMY09/11 primers-M: 100bp DNA ladder, L1: Positive control, L2: Negative control, L3-L7: HPV in cases. (C) 2\% Agarose gel with amplified product of HPV 16 (223bp) M: 100bp DNA ladder, L7: Positive control, L6: Negative control, L1-L5: HPV 16 in cases. (D) $2 \%$ Agarose gel with amplified product of HPV 18 (217bp) M: 100bp DNA ladder, L12: Positive control, L13: Negative control, L1-L11: Samples

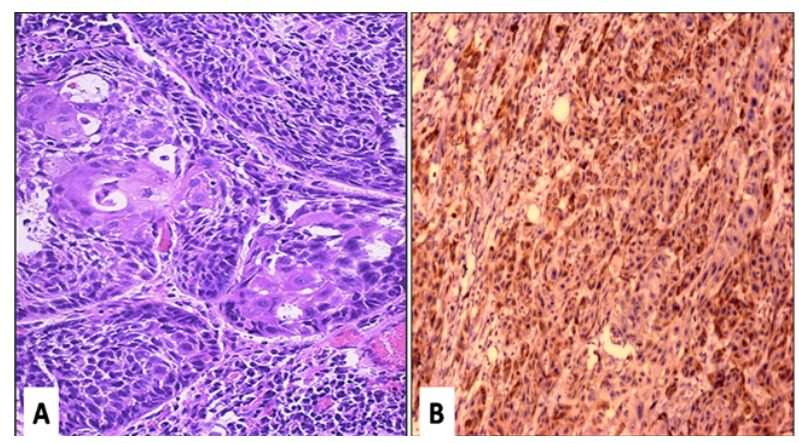

Figure 2. Microphotograph showing. (A) Basaloid morphology, (B) p16 expression in HPV positive cases (DAB x $200 \mathrm{x}$ digital magnification)
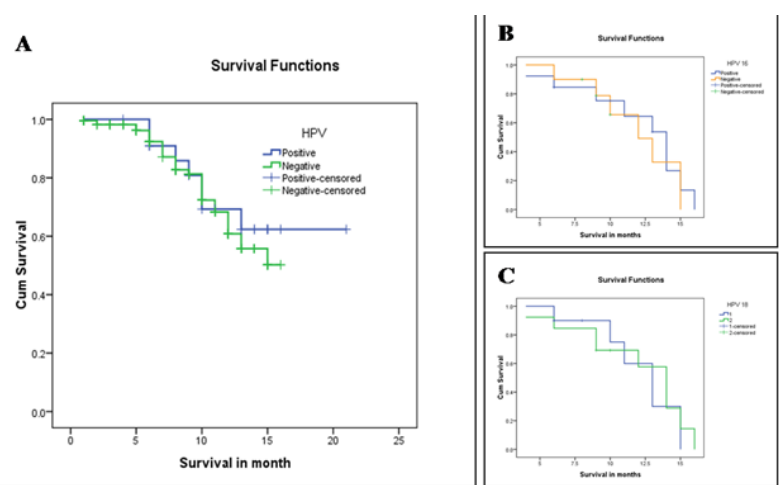

Figure 3. Kaplan-Meier survival curve of patients. (A) According to HPV status, (B) According to HPV16 status, (C) According to HPV18 status. 
Vineeta Singh et al

Table 1. Association of HPV with Clinicopathological, Histopathological, Demographic and Behavioral Characteristics in OSCC Patients

\begin{tabular}{|c|c|c|c|c|c|c|c|}
\hline \multirow{4}{*}{ Characteristics } & \multicolumn{4}{|c|}{ HPV } & \multirow{4}{*}{ OR } & \multirow{4}{*}{$95 \% \mathrm{CI}$} & \multirow{4}{*}{$\mathrm{p}$-value 1} \\
\hline & \multirow{2}{*}{\multicolumn{2}{|c|}{$\frac{\text { Positive }}{(n=23)}$}} & \multirow{2}{*}{\multicolumn{2}{|c|}{$\frac{\text { Negative }}{(n=227)}$}} & & & \\
\hline & & & & & & & \\
\hline & No. & $\%$ & No. & $\%$ & & & \\
\hline \multicolumn{8}{|l|}{ Age in years } \\
\hline$<30$ & 2 & 8.7 & 7 & 3.1 & 2.57 & $0.39-16.86$ & 0.32 \\
\hline $30-40$ & 5 & 21.7 & 73 & 32.2 & 0.616 & $0.15-2.43$ & 0.49 \\
\hline $41-50$ & 7 & 30.4 & 69 & 30.4 & 0.91 & $0.25-3.32$ & 0.89 \\
\hline $51-60$ & 5 & 21.7 & 42 & 18.5 & 1.07 & $0.26-4.29$ & 0.92 \\
\hline$>60$ & 4 & 17.4 & 36 & 15.9 & 1 & Ref. & \\
\hline \multicolumn{8}{|l|}{ Gender } \\
\hline Male & 14 & 60.9 & 186 & 81.9 & 0.34 & $0.13-0.83$ & $0.02 *$ \\
\hline Female & 9 & 39.1 & 41 & 18.1 & 1 & Ref. & \\
\hline \multicolumn{8}{|l|}{ Marital status } \\
\hline Married & 23 & 100 & 223 & 98.2 & \multirow{2}{*}{ NA } & \multirow{2}{*}{ NA } & \\
\hline Unmarried & 0 & 0 & 4 & 1.8 & & & \\
\hline \multicolumn{8}{|l|}{ Residence } \\
\hline Rural & 16 & 69.6 & 159 & 70 & 0.97 & $0.38-2.48$ & 0.96 \\
\hline Urban & 7 & 30.4 & 68 & 30 & 1 & Ref. & \\
\hline \multicolumn{8}{|l|}{ Subsite } \\
\hline $\mathrm{BM}$ & 12 & 52.2 & 115 & 50.7 & 0.99 & $0.35-2.77$ & 0.08 \\
\hline FM & 0 & 0 & 4 & 1.8 & - & - & \\
\hline LA & 4 & 17.4 & 40 & 17.6 & 0.95 & $0.25-3.58$ & 0.94 \\
\hline Palate/Upper alveolus & 0 & 0 & 6 & 2.6 & - & - & - \\
\hline RMT & 1 & 4.3 & 5 & 2.2 & 1.9 & $0.18-19.06$ & 0.58 \\
\hline Tongue & 6 & 26.1 & 57 & 25.1 & 1 & Ref. & \\
\hline \multicolumn{8}{|l|}{ Site } \\
\hline Left & 16 & 69.6 & 116 & 51.1 & 2.18 & $0.86-5.51$ & 0.09 \\
\hline Right & 7 & 30.4 & 111 & 48.9 & 1 & Ref. & \\
\hline \multicolumn{8}{|l|}{ Stage } \\
\hline I & 1 & 4.3 & 21 & 9.3 & 0.47 & $0.05-3.88$ & 0.48 \\
\hline II & 4 & 17.4 & 45 & 19.8 & 0.88 & $0.26-2.93$ & 0.84 \\
\hline III & 7 & 30.4 & 51 & 22.5 & 1.37 & $0.50-3.74$ & 0.53 \\
\hline IV & 11 & 47.8 & 110 & 48.5 & 1 & Ref. & \\
\hline \multicolumn{8}{|l|}{ Smoking } \\
\hline Yes & 12 & 52.2 & 110 & 48.5 & 1.16 & $0.49-2.73$ & 0.73 \\
\hline No & 11 & 47.8 & 117 & 51.5 & 1 & Ref. & \\
\hline \multicolumn{8}{|l|}{ Pan masala } \\
\hline Yes & 8 & 34.8 & 141 & 62.1 & 0.32 & $0.13-0.79$ & $0.01 *$ \\
\hline No & 15 & 65.2 & 86 & 37.9 & 1 & Ref. & \\
\hline \multicolumn{8}{|l|}{ Tobacco } \\
\hline Yes & 19 & 82.6 & 171 & 75.3 & 1.55 & $0.50-4.76$ & 0.43 \\
\hline No & 4 & 17.4 & 56 & 24.7 & 1 & Ref. & \\
\hline \multicolumn{8}{|l|}{ Alcohal } \\
\hline Yes & 7 & 30.4 & 66 & 29.1 & 1.06 & $0.42-2.71$ & 0.89 \\
\hline No & 16 & 69.6 & 161 & 70.9 & 1 & Ref. & \\
\hline
\end{tabular}


Do Human Papilloma Viruses Play Any Role in Oral Squamous Cell Carcinoma in North Indians?

\begin{tabular}{|c|c|c|c|c|c|c|c|}
\hline Present & 3 & 13 & 30 & 13.2 & 0.98 & $0.27-3.51$ & 0.98 \\
\hline Absent & 20 & 87 & 197 & 86.8 & 1 & Ref. & \\
\hline \multicolumn{8}{|l|}{ No habit } \\
\hline Any habit & 21 & 91.3 & 212 & 93.4 & 0.74 & $0.15-3.47$ & 0.7 \\
\hline No habit & 2 & 8.7 & 15 & 6.6 & 1 & Ref. & \\
\hline \multicolumn{8}{|l|}{ Treatment } \\
\hline ABS & 0 & 0 & 3 & 1.3 & - & & \\
\hline $\mathrm{CT}$ & 9 & 39.1 & 62 & 27.3 & 1.52 & $0.30-7.62$ & 0.6 \\
\hline $\mathrm{CT} / \mathrm{RT}$ & 3 & 13 & 34 & 15 & 0.92 & $0.14-6.01$ & 0.93 \\
\hline $\mathrm{CT} / \mathrm{SX} / \mathrm{RT}$ & 2 & 8.7 & 31 & 13.7 & 0.67 & $0.08-5.19$ & 0.7 \\
\hline SX & 7 & 30.4 & 76 & 33.5 & 0.96 & $0.18-5.01$ & 0.96 \\
\hline $\mathrm{SX} / \mathrm{RT}$ & 2 & 8.7 & 21 & 9.3 & 1 & Ref. & \\
\hline \multicolumn{8}{|l|}{ Differentiation } \\
\hline WD & 14 & 60.9 & 129 & 56.8 & 0.65 & $0.07-5.80$ & 0.7 \\
\hline MD & 8 & 34.8 & 92 & 40.5 & 0.52 & $0.05-4.88$ & 0.56 \\
\hline $\mathrm{PD}$ & 1 & 4.3 & 6 & 2.6 & 1 & Ref. & \\
\hline \multicolumn{8}{|l|}{ Cellular morphology } \\
\hline Large & 22 & 95.7 & 226 & 99.6 & 0.09 & $0.01-1.61$ & 0.1 \\
\hline Basaloid & 1 & 4.3 & 1 & 0.4 & 1 & Ref. & \\
\hline \multicolumn{8}{|l|}{ Node } \\
\hline Present & 15 & 65.2 & 132 & 58.1 & 1.34 & $0.55-3.31$ & 0.51 \\
\hline Absent & 8 & 34.8 & 95 & 41.9 & 1 & Ref. & \\
\hline \multicolumn{8}{|l|}{ Recurrence $(n=140)$} \\
\hline Recurrence & 1 & 9.1 & 9 & 7 & 1.33 & $0.15-11.61$ & 0.79 \\
\hline No recurrence & 10 & 90.9 & 120 & 93 & 1 & Ref. & \\
\hline \multicolumn{8}{|l|}{ Survival } \\
\hline Dead & 7 & 30.4 & 58 & 25.6 & 1.27 & $0.49-3.25$ & 0.61 \\
\hline Alive & 16 & 69.6 & 169 & 74.4 & 1 & Ref. & \\
\hline \multicolumn{8}{|c|}{ p16 Protein expression $(n=23)$} \\
\hline Positive & 9 & 39.1 & 7 & 30.4 & 1.46 & $0.43-4.9$ & 0.54 \\
\hline Negative & 14 & 60.9 & 16 & 69.6 & 1 & Ref. & \\
\hline
\end{tabular}

$1 \mathrm{p}$ value $<0.05$ by Binary logistic regression method.; Abbreviations: HPV- Human Papilloma Virus, OR-Odds Ratio, BM-Buccal Mucosa, FMfloor of Mouth, LA-Lower Alveolus, RMT-Retro Moral trigone, SX = Surgery, CT=Chemotherapy, CT/RT=Chemotherapy and Radiotherapy both, SX/RT=Surgery and Radiotherapy both, CT/SX/RT=Chemotherapy, Surgery and Radiotherapy, WD- Well Differentiated, MD- Moderately Differentiated, PD- Poorly Differentiated

Table 2. HPV Subtypes in OSCC Patients

\begin{tabular}{lcc}
\hline HPV Result & No. of Patient & $\%$ \\
\hline HPV positive cases & 23 & 9.2 \\
HPV negative cases & 227 & 90.8 \\
HPV Types & 7 & 30.4 \\
HPV16 only & 4 & 17.4 \\
HPV18 only & 6 & 26.1 \\
HPV16 and 18 co-infection & 6 & 26.1 \\
Negative for HPV 16/18 or suspected subtypes other than 16/18 & & \\
\hline
\end{tabular}

Abbreviation: HPV- Human Papilloma Virus

DNA of both HPV 16 and 18 subtypes and $26.1 \%$ cases were negative for both 16 and 18 or supposed to had HPV subtypes other than 16/18 (Table 2, Figure 1C\& D).

Correlation of HPV 16 and 18 with clinicopathological variables
Association of HPV type 16 \& 18 with all clinical, demographic \& behavioral profile of patients were evaluated but it was found to be shown no association with any of these (data not shown).

Correlation of HPV with Survival of Patients

Asian Pacific Journal of Cancer Prevention, Vol 16, 2015 
Vineeta Singh et al

Table 3. Association of Survival of Patients with HPV Presence and Its Subtypes.

\begin{tabular}{lc}
\hline HPV Status & Median Survival in Month \\
\hline HPVa & \\
Positive & 16.5 \\
Negative & 12.9 \\
Total cases & 15.6 \\
HPV16b & \\
Positive & 14 \\
Negative & 12 \\
HPV18c & \\
Positive & 13 \\
Negative & 14 \\
\hline
\end{tabular}

Log Rank test ap $=0.62, \mathrm{bp}=0.68, \mathrm{cp}=0.72$ (Insignificant); Abbreviation: HPV- Human Papilloma Virus

According to Log rank test median survival of HPV positive patients was better (16.5) compared to HPV negative patients (12.9) but the difference was not significant $(\mathrm{p}=0.62)$ (Figure 3A, B \& C). The survival status of patients in the study is shown in Table 3 .

\section{Correlation of $H P V$ with $p 16$ protein expression}

p16 expression was evaluated in all HPV positive cases and equal number of HPV negative cases $(n=23)$ that were selected randomly. Diffuse nuclear staining with some cytoplasmic positivity for $\mathrm{p} 16$ protein was seen in $39.13 \%$ HPV positive patients and $30.43 \% \mathrm{HPV}$ negative patients (Table 1, Figure 2B). p16 over expression was not associated with the presence of HPV ( $\mathrm{p}=0.54)$.

\section{Discussion}

HPV has been identified as a prime suspect in the etiology of HNSCC due to their morphological similarities with genital epithelia and their ability to transform and immortalize oral keratinocytes (Termine et al., 2008). Speculation on the role of HPV in the etio-pathogenesis of oral carcinoma has been voiced worldwide. We have explored the frequency and major genotypes of HPV in 250 histologically confirmed cases of OSCC in NorthIndian population.

The overall prevalence of HPV associated OSCC at worldwide level varies from 0-30\%.In North America $5.9 \%$ positivity was reported by Mark W. Lingen., 2013, in Canada 4\% by Jarry Machado et al., 2010, 27.5\% in China by Li-Li Gan et al., 2014 and only 3\% in Bangladesh by Mahmuda Akhter et al., 2013.

Most Indian studies have reported prevalence of HPV associated OSCC between 15-37.9\% (Priya et al., 2005; Alok et al., 2006; Chaudhary et al., 2013) with an exception in southern India where higher prevalence of HPV (70.6\%) was reported (Kulkarni et al., 2011). Our study is in concordance with previous studies and shows that HPV was associated in $9.2 \%$ of OSCC cases with HPV 16 showing higher (30.4\%) prevalence than HPV 18 (17.47\%). In one fourth of the cases it is not single subtype which was present, but the co-infection of 16/18. Tobacco and betel nut chewing habits were the major etiological factors involved in our study population.
In contrast to oropharyngeal cancer, oral cancer and other HNSCC occasionally harbor HPV (Dayyani et al., 2010; Machado et al., 2010). Its presence is strongly associated with oropharynx, most notably in tonsils and base of tongue (El-Mofty, 2003; Gillison et al., 2004). This might be due to the fact that these tumors may constitute an etiologically different subgroup within head and neck tumors. HPV might play a role in progression of premalignant lesions to advanced cancer form (Miller et al., 2001) but evidences in this direction are not sufficient. Low prevalence of HPV in oral cavity carcinoma was reported by Jerry Machado et al., 2010. Luca Scapoli et al., 2008 also found a very low prevalence of HPV in oral cavity (2\%) and demonstrated no significant correlation of HPV in OSCC.

Association of HPV with other factors is also controversial worldwide, for instance Luciano MarquesSilva et al., 2012 reported no association of HPV positivity with age. To the contrary Abdul Samad Gichki et al., 2012 reported higher HPV incidence between 20-59 years of age. Jerry Machado et al., 2010 found no significant association between HPV presence and smoking, alcohol status, tumor differentiation, stage and survival. Our study is in concordance with previous reports of no significant association of HPV positivity with age, marital status, demographic profile, tumor stage, grade and site of tumor. HPV in our case series was significantly associated with male gender $(\mathrm{p}=0.02)$ this is might be due to the fact that HNSCC is more common in males compared to females because of the presence of traditional risk factors here.

Earlier studies report that majority of HPV related carcinomas of the oropharynx are nonkeratinizing squamous cell carcinoma (NKSCC) with a characteristic basaloid cellular morphology and these tumors were found to be more responsive to treatment with a favorable patient outcome and good prognosis. But HPV positive OSCC, unlike oropharynx, do not exhibit distinct morphology and have poor prognosis (El-Mofty et al., 2014). Our study is in agreement with studies where HPV positive cases did not demonstrate basaloid morphology $(\mathrm{p}=0.10)$ and we also found no significant differences in survival outcome $(p=0.62)$ between HPV positive and negative cases.

It is assumed that carcinogenic potential of HPV increases with viral integration to host genome (Spence et al., 2005). Smoking induces DNA damage which may favor the integration of HPV to human genome at these sites (Luo et al., 2005) thus enhancing the oncogenic potential of virus. In our study majority of HPV positive cases $(91.3 \%)$ had one or multiple of the tobacco related habits like tobacco and pan masala chewing/smoking. We have observed significant relationship of HPV with pan masala chewing (0.01), a habit peculiar to the Indian subcontinent. The possibility of this may be the local injury caused to buccal mucosa during tobacco/pan masala chewing creates atmosphere for virus to infect easily.

The limitation of the present study was that we were unable to evaluate the oncogenic expressions of HPV E6/E7 in our case series due to scarce sample amount. Furthermore, due to lack of relevant information regarding behavioral history of patients, the route of transmission of virus is not recognized here. The FDA approved 
hybrid capture method was not implemented in our cases. However we have utilized both in-house conventional PCR assay and a kit based real time PCR analysis to confirm HPV presence. Further sub typing for 16 and 18 also show independent positive results. Hence we feel confident about the presence of HPV in our cases. Despite of some limitations our data is contributing needful information regarding HPV presence in OSCC of North Indian population that will be useful for the future treatment implications.

HPV positive cancers usually show over-expression of p16, while the loss of the p16 expression by deletion, hypermethylation or mutation is common in tobacco related cancers. Therefore, p16 up regulation is an indication of expression of viral oncogenes and we can expect the presence of HPV (Tran et al., 2007; Vidal et al., 2008; Klussmann et al., 2009; Ahmed et al., 2012), but its relevance for the site of HNSCC other than oropharynx is ambiguous. In our cases presence of HPV was not significantly associated with p16 expression and all p16 positive cases had history of tobacco consumption. It is possible that tobacco related oncogenic pathway coexisted with HPV related events in our cases. Hence, p16 expression was not found to be a reliable marker for HPV presence in our population. Our findings are in concordance with Pradit Rushatamukayanunt et al., 2014 who also could not relate p16 expression for HPV infection in OSCC.

In conclusion, our findings illustrate that $9.2 \%$ OSCC cases harbor HPV in North Indian population which is slightly lower than that observed in previous Indian studies and we report tobacco as a major risk factor in both HPV negative as well as positive cases. Therefore the independent role of HPV in the causation of oral cancer is difficult to evaluate in our case series due to the strong confounding influence of tobacco. We also find that p16 expression is not a reliable marker in the oral cavity to assess the potential etiologic role of HPV. Further studies on larger and well defined population are needed to elucidate the role of HPV induced oral oncogenesis and co-carcinogenesis pathways need to be explored.

\section{Acknowledgements}

The authors wish to thank all those who have cooperated in the study. Present work was funded by the Institutional Research Grant, Dr. Ram Manohar Lohia Institute of Medical Sciences, Lucknow and Rajiv Gandhi National Fellowship, University Grant Commission (UGC), New Delhi, India (Vineeta Singh; F1-17.1/201112/RGNF-SC-UTT-2841).

\section{References}

Abdul Samad Gichki, Waranun Buajeeb, Sombhun Doungudomdacha, et al (2012). Detection of human papillomavirus in normal oral cavity in a group of pakistani subjects using real-time PCR. Asian Pac J Cancer Prev, 13, 2299-2304.

Ahmed HG, Mustafa S, Warille E (2012). Human papilloma virus attributable head and neck cancer in the Sudan assessed by p16INK4a immunostaining. Asian Pac J Cancer Prev, 13, 6083-6.

AK Chaudhary, S Pandya, M Singh, et al (2013). Identification of high-risk human papillomavirus-16 and -18 infections by multiplex PCR and their expression in oral submucous fibrosis and oral squamous cell carcinoma. Head Neck Oncol, 5, 4 .

Alok Mishra, Alok C Bharti, Prishla Varghese, et al (2006). Differential expression and activation of NF-jB family proteins during oral carcinogenesis: Role oh high risk human papilloma infection. Int J Cancer, 119, 2840-50.

Anil K Chaturvedi, Eric A Engels, William F Anderson, et al (2008). Incidence trends for human papillomavirus -related and -unrelated oral squamous cell carcinomas in the united states. J Clin Oncol, 26, 612-19.

Balaram P, Nalinakumari KR, Abraham E, et al (1995). Human papilloma virus in 91 oral Indian betel quid chewers: High prevalence and multiplicity of infections. Int J Cancer, $\mathbf{6 1}$, 450-4.

Byakodi R, Byakodi S, Hiremath S, et al (2012). Oral cancer in India: an epidemiologic and clinical review. J Community Health, 37, 316-9.

Dayyani F, Etzel CJ, Liu M, et al (2010). Meta- analysis of the impact of human papillomavirus (HPV) on cancer risk and overall survival in head and neck squamous cell carcinomas (HNSCC). Head Neck Oncol, $2,15$.

D'Costa J, Saranath D, Dedhia P, et al (1998). Detection of HPV16 genome in human oral cancers and potentially malignant lesions from India. Oral Oncol, 34, 413-20.

D'Souza, A R Kreimer, R Viscidi, et al (2007). Case-control study of human papillomavirus and oropharyngeal cancer. New Engl J Med, 356, 1944-56.

El-Mofty SK, Lu DW (2003). Prevalence of human papillomavirus type 16 DNA in squamous cell carcinoma of the palatine tonsil, and not the oral cavity, in young patients: A distinct clinicopathologic and molecular disease entity. Am J Surg Pathol, 27, 1463-70.

Elaine M Smith, Justine M Ritchie, Kurt F Summersgill, et al (2004). Age, sexual behavior and human papillomavirus infection in oral cavity and oropharyngeal cancers. Int J.Cancer, 108, 766-72.

Freddie Bray, Jian-Song Ren, Eric Masuyer, et al (2013). Global estimates of cancer prevalence for 27 sites in the adult population in 2008. Int J Cancer, 132, 1133-45.

Gillison ML (2004). Human papillomavirus-associated head and neck cancer is a distinct epidemiologic, clinical, and molecular entity. Semin Oncol, 31, 744-54.

Hafkamp HC, Manni JJ, Haesevoets A, et al (2008). Marked Differences in Survival Rate between Smokers and Nonsmokers with HPV 16-Associated Tonsillar Carcinomas. Int J Cancer, 122, 2656-64.

JC De Vicente, LMJ Gutierrez, AH Zapatero, et al (2004). Prognostic significance of $\mathrm{p} 53$ expression in oral squamous cell carcinoma without neck node metastases. Head Neck, 26, 22-30.

Jerry Machado, Patricia P Reis, Tong Zhang, et al (2010). Low prevalence of Human Papilloma virus in oral cavity carcinoma. Head Neck Oncol, $2,6$.

Judit A. Nemes, Levente Deli, ZoltánNemes, et al (2006). Expression of p16 (INK4A), p53, and Rb proteins are independent from the presence of human papillomavirus genes in oral squamous cell carcinoma. Oral Surg Oral Med Oral Pathol Oral Radiol Endod, 102, 344-52.

Klussmann JP, Mooren JJ, Lehnen M, et al (2009). Genetic signatures of HPV-related and unrelated oropharyngeal carcinoma and their prognostic implications. Clin Cancer Res, 15, 1779-86. 


\section{Vineeta Singh et al}

Lassen P, Eriksen JG, Hamilton-Dutoit S, et al (2009). Effect of HPV-associated p16INK4A expression on response to radiotherapy and survival in squamous cell carcinoma of the head and neck. J Clin Oncol, 27, 1992-98.

Li-Li Gan, Hao Zhang, Ji-HuaGuo, et al (2014). Prevalence of human papillomavirus infection in oral squamous cell carcinoma: a case-control study in Wuhan, China. Asian Pac J Cancer Prev, 15, 5861-65.

Luo LZ, Werner KM, Gollin SM, et al (2004). Cigarette smoke induces anaphase bridges and genomic imbalances in normal cells. Mutat Res, 554, 375-85.

Luca Scapoli, Annalisa Palmieri, Corrado Rubini, et al (2009). Low prevalence of human papillomavirus in squamous- cell carcinoma limited to oral cavity proper. Modern Pathol, 22, 366-72.

Luciano Marques-Silva, Lucyana Conceição Farias, Carlos Alberto De Carvalho Fraga, et al (2012). HPV-16/18 detection does not affect the prognosis of head and neck squamous cell carcinoma in younger and older patients. Oncol Letters, 3, 945-49.

Maura L Gillison, Wayne M Koch, Randolph B. Capone, et al (2000). Evidence for a causal association between human papillomavirus and a subset of head and neck cancers. $J$ National Cancer Inst, $\mathbf{9 2}, 9$.

Marur S, D'Souza G, Westra WH, et al (2010). HPV-associated head and neck cancer: a virus-related cancer epidemic. Lancet Oncol, 11, 781-9.

MahmudaAkhter, Liaquat Ali, Zahid Hassan, et al (2013). Association of human papilloma virus infection and oral squamous cell carcinoma in bangladesh. J Health Popul Nutr, 31, 65-9

Mark W. Lingen, Weihong Xiao, Alessandra Schmitt (2013). Low etiologic fraction for high-risk human papillomavirus in oral cavity squamous cell carcinomas.Oral Oncol, 49, 1-8.

Miller CS, Johnstone BM (2001). Human papillomavirus as a risk factor for oral squamous cell carcinoma: a meta-analysis, 1982-1997. Oral Surg Oral Med Oral Pathol Oral Radiol Endod, 91, 622-35

Mia Hashibe, Paul Brennan, Shu-chun Chuang, et al (2009). Interaction between tobacco and alcohol use and the risk of head and neck cancer: pooled analysis in the inhance consortium. Cancer Epidemiol Biomarkers Prev, 18, 541-50.

M Rani, S Bonu, P Jha, et al (2003). Tobacco use in India: prevalence and predictors of smoking and chewing in a national cross sectional household survey. Tob Control, 12,4.

P.E.Gravitt,C.L.Peyton, T.Q.Alessi, et al (2000). Improved amplification of genital human papillomaviruses. J Clin Microbiol, 38, 357-61.

Priya Koppikar, Ethel-Michele deVilliers, Rita Mulherkar (2005). Identification of human papillomaviruses in tumors of the oral cavity in an Indian community. Int J Cancer, 113, 946-50.

Pradit Rushatamukayanunt, Kei-ichi Morita, Sho Matsukawa, et al (2014). Lack of association between high-risk human papillomaviruses and oral squamous cell carcinoma in Young Japanese Patients. Asian Pac J Cancer Prev, 15, 4135-41.

Samir K El-Mofty (2014). Histopathologic risk factors in oral and oropharyngeal squamous cell carcinoma variants: An update with special reference to HPV-related carcinomas. Med Oral Patol Oral Cir Bucal, 19, 377-85.

Sharma H, Singh A, Sharma C, et al (2005). Mutations in the mitochondrial DNA D-loop region are frequent in cervical cancer. Cancer Cell Int, 5, 34 .

Spence AR, Franco EL, Ferenczy A (2005). The role of human papillomavirus in cancer. Am J Cancer, 4, 49-64.

Suyamindra S Kulkarni, Sujayendra S Kulkarni, Priyanka P Vastrad, et al (2011). Prevalence and distribution of high risk human papillomavirus (HPV) types 16 and 18 in carcinoma of cervix, saliva of patients with oral squamous cell carcinoma and in the general population in Karnataka, India. Asian Pac J Cancer Prev, 12, 645-48.

Termine N, Panzarella V, Falaschini S, et al (2008). HPV in oral squamous cell carcinoma vs head and neck squamous cell carcinoma biopsies: a meta-analysis (1988-2007). Ann Oncol, 19, 1681-90.

Tran N, Rose BR, O'Brien CJ (2007). Role of human papillomavirus in the etiology of head and neck cancer. Head Neck, 29, 64-70.

Vidal L, Gillison ML (2008). Human papillomavirus in HNSCC: recognition of a distinct disease type. Hematol Oncol Clin North Am, 22, 1125-42. 